\title{
Usage of Mobile Devices as Collaborative Tools for Education and Preparation of Official Exams
}

\author{
López, J.P.; Cerezo, A.; Menéndez, J.M.
}

\author{
Ballesteros, J. P.
}

\begin{abstract}
Preparation of official examinations and oppositions is a difficult task in which new technologies related to mobile Web 2.0 play an important role, because they can improve the learning methodology. A collaborative platform based on a smartphone application was developed for helping students to prepare an official examination which, in this concrete case, is the preparation of the exam for obtaining the accreditation for touristic guides of the Agència Valenciana del Turisme. The app enables the users to collaborate in the improving the platform sending their own questions and opinions about the development. The gamification of the process helps students increase their motivation to study. The application Turisme GVA had a very good reception with a high amount of downloads, also supported with opinions from users and real collaboration to improve the functioning and interface. All this interaction and exchange of information, complemented with final surveys and statistics, revealed a good level of satisfaction from users in the usage of smartphones to increase students' motivation and their degree of involvement for reaching a common goal. This project is a pioneer in the introduction and usage of new technologies in e-learning and mobile education.
\end{abstract}

Keywords- e-learning, gamification, social networks, smartphone application, mobile web 2.0, examination, selfassessment

\section{INTRODUCTION}

$\mathrm{M}$ OTIVATION and engagement are primary for the completion of a task, especially in education, in which boredom or lack of engagement are sources of distraction [1]. Gamification is becoming a popular term for describing games as a source of educational motivation disguised of entertainment to solve problems and engage audiences [2]. According to Nielsen Report [3], in 2013 the monthly average time spent per person by platform in the U.S. is 185 hours for television, 27 hours for computer, and 35 hours for mobile devices. A $9 \%$ of those 35 hours is dedicated to games, while education is not even a category for education in the report. Therefore and increasingly, consumers are using their smartphones for different purposes and education is still an emergent usage with a high potential for mobile devices.

Also, m-learning (mobile learning) term [4] is commonly used as an extension of e-learning applied to mobile devices, such as tablets or smarthphones. In the future, the vision of education implies the insertion of game-based, immersive, social and interactive elements [5]. Online self-assessment tests is considered as a good formative strategy for students [6] and means a good experience to be exported to mobile devices apps. Tools for collaboration designed for the application were taken into account for the implementation. Collaborative learning among students have beneficial effects because of the increasing motivation and the social relations improvement [7].

The experimental application developed for the preparation of the examination for obtaining the accreditation for touristic guides offered very satisfactory results, demonstrating the motivation increase related to new technologies and collaborative tools.

In the following text, a state of the art and related studies is made in Section I. Section II describes the environment and aims and questions to be answered in Section III, which includes the development of the application, while Section IV includes the results of tests. Finally, Section IV concludes the paper.

\section{ENVIRONMENT AND OBJECTIVES}

The call for the official examination [8] for obtaining the accreditation for touristic guides of the Agència Valenciana del Turisme appeared on Diari Oficial de la Comunitat Valenciana $28^{\text {th }}$ October 2013, and the theoretic examination took place on November 2014 , i.e. more than a year to prepare the tests.

Among the 618 participants which initially accepted the call, only 465 of them (approximately $75 \%$ of the candidates) passed the final examination.

The examination consisted in a theoretical test with four optional answers, being only one correct, and an oral exam to demonstrate the abilities of the candidate as a touristic guide. The list of topics for the theoretical examination included questions for four different subjects: assistance to touristic groups, socio-political environment of the Valencian Community, Art and History of the Valencian Community and Geography of the Valencian Community.

The objective was developing a mobile devices application adapted to this contents, as a simulation of the examination, and collaborative to increase motivation.

The application was distributed through different way, such as social networks and app markets [9], for free downloading. 


\section{APPLICATION DESCRIPTION}

The application scheme is described in Fig. 1. The app programmed for smartphones connects the users with a questions database simulating the real examination in its four categories. Additionally, the app enables the users to send their own questions to increase the motivation.



Fig. 1. GVA Turisme App scheme

Users are presented each multiple-choice question with a timer of 30 seconds. The timer means a simulation of the examination time, which consists in 100 questions for 40 minutes, i.e. a question for each 24 seconds and an extra time for reading the four choices. The timer trains the student to quickly read the question and answer. After the student has answered the question, the app reveals the real answer for selfassessment and if the user was right in the answer.

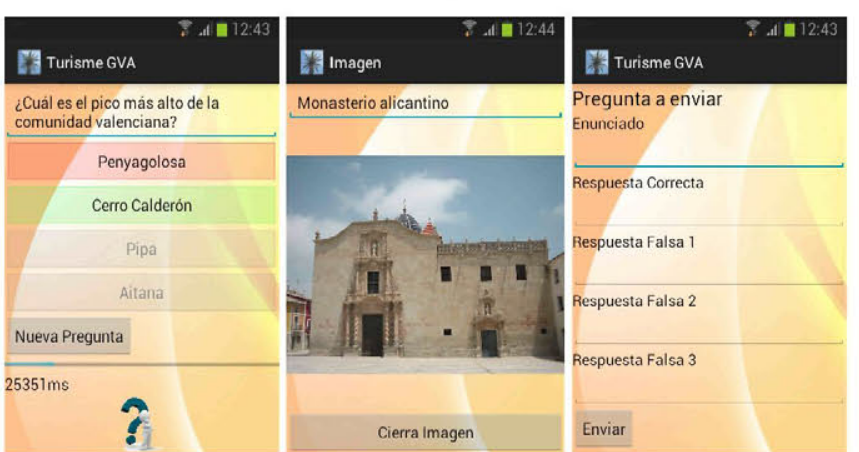

Fig. 2. Sample of interface for simple question (left), question with image (center) and collaborative tool (right)

Samples of the interface are shown in Fig. 2. The collaborative tool enables users to send their own questions to participate in the development of the app. Also, most the questions show an image to help in the study, to avoid random answering, and facilitate learning.

\section{RESULTS}

The application was downloaded from more than 75 users who was preparing the examination, and more than 30 questions and commentaries were sent to the developers. Questions sent were accepted and included in the database. Users who sent questions to improve the task commented the motivation related after seeing their questions in the app.

Downloading the app was completely free through the common markets in the internet.
The rest of users' comments were all of them positive, thanking the developers for designing the application, which is very useful for the exam and help them to prepare the examination.

All of the users that answered to the final survey said that they have passed the examination. Concluded that the reason of passing the exam was due to the application would be difficult, but everybody coincide that it was very helpful.

\section{CONCLUSIONS}

The application developed in the project offers the chance of increasing flexibility and mobility, adapting the learning to any environment. Users can study anytime, anyplace, without the necessity of carrying books and paper. The concept of study become independent of a textbook is, increasing convenience.

One of the key factors of the application is the collaboration among users for improving the tool in benefit of all. The idea of sending questions to the database enables the user to be a participant in the process of development, sharing responsibilities with the code developers.

As described by users, the application is useful for preparing this examination because simulates the real examination environment and enables easily studying.

Additionally, the architecture of the system is exportable to other subjects, because it enables the adaptation to other official exams with easy modifications and the collaboration of other users and exchange of information.

\section{ACKNOWLEDGMENT}

The work developed by UPM in collaboration with I.E.S. Villa de Vallecas was performed in the framework of project TEC2012-38402-C04-01 HORFI, which is partially funded by the Spanish Ministry of Science and Innovation.

\section{REFERENCES}

[1] Huang, W. H. Y., \& Soman, D. (2013). Gamification Of Education. Research Report Series: Behavioural Economics in Action.

[2] Zichermann, G., \& Cunningham, C. (2011). Gamification by design: Implementing game mechanics in web and mobile apps. "O'Reilly Media, Inc.".

[3] Nielsen. (2014) The Digital Consumer Report 2014 Nielsen.

[4] Cochrane, T., \& Bateman, R. (2010). Smartphones give you wings: Pedagogical affordances of mobile Web 2.0. Australasian Journal of Educational Technology, 26(1), 1-14.

[5] de Freitas, S., \& Liarokapis, F. (2011). Serious Games: A New Paradigm for Education?. In Serious games and edutainment applications (pp. 9-23). Springer London.

[6] Ćukušić, M., Garača, Ž., \& Jadrić, M. (2014). Online self-assessment and students' success in higher education institutions. Computers \& Education, 72, 100-109.

[7] Cheong, C., Bruno, V., \& Cheong, F. (2012). Designing a mobile-appbased collaborative learning system. Journal of Information Technology Education: Innovations in Practice, 11(1), 94-119.

[8] Turisme GVA. Convocatoria 2013 de Guía de turismo. http://www.turisme.gva.es/opencms/opencms/turisme/es/contents/tramit acion/guia turistico/guia de turismo convocatoria 2013.html

[9] Google Play Market: Turisme GVA. Application, 2014. https://play.google.com/store/apps/details?id=com.turismo.realidad 